\title{
ANÁLISE DOS HOMICÍDIOS OCORRIDOS EM JUIZ DE FORA ENTRE OS ANOS DE 1980 A 2012 E SUA RELAÇÃO COM AS CONDIÇÕES CLIMÁTICAS.
}

\author{
Monique Cristine de Britto \\ Professora de Geografia no Colégio Tiradentes da Polícia Militar de Juiz de Fora e \\ Mestranda em Geografia, PPGEO/UFJF
}

Cássia de Castro Martins Ferreira

Professora do Programa de Pós-Graduação em Geografia e Doutora em Geografia Física

\begin{abstract}
RESUMO
Influenciados pelas concepções Lacaz (1972), Anderson (1987; 1989), Durkheim (2001), Mendonça (2001), Butke (2010) e Anjos (2003), descrevemos e analisamos os padrões de distribuição temporal dos homicídios registrados em Juiz de Fora-MG no período de 1980 a 2012, integrando dados do Sistema Integrado de Mortalidade (SIM/DATASUS/MS), da Polícia Militar e da Polícia Civil, associando tais informações as variáveis climáticas, como temperatura, precipitação, nebulosidade e pressão atmosférica e, dentre estas, uma maior propensão às variáveis térmicas, analisadas por meio dos registros de temperatura instantânea, temperatura máxima e temperatura mínima, disponibilizados pelo Laboratório de Climatologia e Análise Ambiental da UFJF. Após a tabulação das informações, das representações gráficas e das análises de correlação, os resultados demonstraram que apesar das melhorias nas condições de desenvolvimento humano municipal, as taxas de homicídios na cidade aumentaram. As informações de crimes violentos e óbitos por homicídios foram os que apresentaram os mais fortes coeficientes de correlação com as variáveis envolvidas, sinalizando para quedas nos períodos mais frios e picos na primavera e no verão.
\end{abstract}

Palavras-chave: homicídios, clima, Juiz de Fora.

ANALYSIS OF HOMICIDES OCCURRING IN JUIZ DE FORA BETWEEN THE YEARS OF 1980 TO 2012 AND THE RELATION WITH THE CLIMATIC CONDITIONS

ABSTRACT: Influenced by ideas Lacaz (1972), Anderson (1987, 1989), Durkheim (2001), Mendoza (2001), Butke (2010) and Angels (2003), describe and analyze the temporal distribution patterns of homicides in Judge MG-off in the period from 1980 to 2012, incorporating data from the Integrated System (SIM / DATASUS / MH), Military Police and Civil Police, associating information such climatic variables such as temperature, precipitation, cloudiness and atmospheric pressure and among these, a greater propensity to thermal variables, as shown by the records of instantaneous temperature, maximum temperature and minimum temperature, provided by the Laboratory of Climatology and Environmental Analysis FUJF. After tabulating the information and graphic representations of the correlation analysis, the results showed that despite improvements in the conditions of municipal human development, the homicide rates in the city increased. Information of violent crime and homicide deaths were those with the strongest correlation coefficients with the variables involved, signaling declines during the colder periods and peaks in spring and summer.

Keywords: Homicide, climate, Juiz de Fora.

\section{1-INTRODUÇÃO}

O presente artigo é parte de uma pesquisa de mestrado onde buscamos evidenciar, verificar e analisar a dinâmica temporal e espacial dos homicídios registrados em Juiz de Fora-MG entre os anos de 1980 a 2012 delineando associações entre as variáveis climatológicas e socioeconômicas. A associação entre as condições climáticas e a saúde humana é tema de interesse de um vasto ramo de disciplinas, muitas vezes desembocando na concepção do Ano 9 - Vol. 13 - JUL/DEZ 2013 
determinismo climático. Contudo alguns estudos, como Lacaz (1972), Anderson (1987; 1989), Durkheim (2001), Mendonça (2001), Butke (2010), e Anjos (2003) avançaram nesta perspectiva, e de uma maneira muito cautelosa, sinalizaram para uma possível influência entre o clima e os comportamentos violentos, dentre eles, os criminalizados, como os homicídios. Ao discutirem as concepções de violência, Hayeck (2009), Adorno (2002) e Waiselfisz (2011) destacam como ela está cada vez mais presente no cotidiano da sociedade brasileira, vinculada a mídia, às concepções de crime e, no seu grau mais extremo, aos homicídios, intensificando o sentimento de medo e insegurança no urbano.

Numerosos estudos, principalmente desenvolvidos em países desenvolvidos, tem notado que crimes agressivos são mais frequentes em regiões geográficas, estações e/ou meses mais quentes. Por exemplo, Brearley (1932), ao analisar as ocorrências de homicídios entre os anos de 1918 a 1929, nos Estados Unidos, notou que estes foram mais frequentes nos estados do sul. Para Guerry apud Anderson (1989), ao estudar a distribuição dos crimes contra pessoa e crimes contra a propriedade, entre os anos de 1826 a 1830, na França, as regiões mais quentes, estariam mais associadas a crimes violentos, concluindo que no sul as ocorrências de crimes contra a pessoa foi duas vezes superior no centro e no norte, enquanto que, os crimes contra a propriedade, foram duas vezes mais prevalentes no norte. Com resultados semelhantes, Lombroso (1911) apontou que taxas maiores de homicídios foram relativamente altas no sul da Itália, moderadas no centro e baixas no norte, enquanto que, o roubo qualificado foi mais comum no centro e, igualmente, menos comum no norte e sul da Itália.

No início do século XXI, influenciado pelas concepções de Carlos Augusto Figueiredo Monteiro, E. Durkheim (2001), E. Huntington (apud Sorre, 1984), M. Sorre (1984), A. Serra (1954), S. Felix (1989), G. Moser (1992) e M.Z. Rouquayrol (1993), Francisco Mendonça, na obra Clima e Criminalidade (2001), desenvolveu um ensaio analítico da correlação entre a temperatura do ar e a incidência de criminalidade urbana nos macro compartimentos climáticos nacionais, mesclando extremos térmicos, os índices de conforto do ser humano, a qualidade de vida nas cidades, Índice de Desenvolvimento Humano e Índice de Condição de Vida. Dentre os resultados, apontou a existência de correlações significativas para as cidades do Rio de Janeiro, Recife, Manaus e Porto Alegre, sendo que a cidade de São Paulo se aproximou dos índices destas. Teresina, Goiânia e Cuiabá, apresentaram linhas de temperatura e criminalidade com relativo paralelismo em alguns meses do ano, destacando-se os períodos de primavera e o outono e, os maiores índices de criminalidades, referentes às três cidades, ocorreram no verão prolongado. As cidades de Rio de Janeiro, Recife, São Paulo, Curitiba e Porto Alegre, mostraram curvilinearidade entre as duas variáveis, quando novamente, o mês de dezembro apresentou os maiores índices de criminalidade, com exceção de São Paulo, observado nos meses de janeiro e abril. Os índices mais baixos foram registrados nos três meses de 
inverno em Recife, no mês de julho em Porto Alegre, em setembro no Rio de Janeiro e em São Paulo.

Estudando diversos crimes (homicídios, lesão corporal, violação a domicílio, roubo sem arma, roubo com arma, atentado ao pudor, porte de tóxico, embriaguez e violência à mulher) referentes à cidade de Maringá, no período de 1985 a 2001, Anjos (2003) também notou que no verão as taxas criminais totais foram maiores, momento que coincide com as datas festivas, como o Natal, final de ano, carnaval, férias e as maiores temperaturas. Para a autora, esses fatores atuariam favorecendo o uso de consumo de bebidas alcoólicas e uso de tóxicos. Em sua pesquisa, os totais foram mais acentuados nos meses de outubro a março, com relativa diminuição entre abril a setembro, constatando maiores totais em dezembro e janeiro, enquanto os meses de junho, julho e agosto, concentraram os menores valores. Ao longo da pesquisa apontou como variáveis mais significativas, a temperatura média, pressão atmosférica e temperatura máxima.

Por ser um tema que suscita questionamentos variados, seja na meteorologia, na climatologia, na psicologia, sociologia, economia, geografia, entre outros ramos, sobretudo quando se observa a correlação entre a sazonalidade e os registros de homicídios, estruturamos este artigo, visando responder a seguinte questão: comparativamente aos estudos apresentados anteriormente, Juiz de Fora-MG, apresentaria correlações entre os crimes violentos, particularmente, os homicídios, e as variações dos elementos climáticos, analisados mensalmente e sazonalmente?

\section{2-MATERIAIS E MÉTODOS}

O recorte temporal deveu-se a disponibilidade das informações sobre homicídios e a relevância em congregar os dados disponibilizados pelo Sistema Integrado de Mortalidade, da Polícia Militar e da Polícia Civil, referentes, respectivamente aos óbitos por homicídios (1980 a 2010), à criminalidade violenta (2005-2011) e aos homicídios (2010 a 2012).

Os dados referentes aos óbitos foram selecionados em meio aos óbitos do tipo violência e segundo o local de ocorrência do fato (município), disponibilizado pelo Sistema Integrado de Mortalidade, vinculado ao Ministério da Saúde. Os registros de criminalidade violenta são provenientes da $4^{a}$ Região Integrada de Segurança Pública, localizada em Juiz de Fora e reuniram os totais de ocorrências classificadas pelos policiais militares como homicídios (tentado e consumado), roubo e assalto, estupro (tentado e consumado), extorsão mediante sequestro e sequestro e cárcere privado, vinculados à área urbana.

Estes dados são amplamente utilizados para compor o índice de Criminalidade Violeta do Estado de Minas Gerais, sendo a base para a estruturação dos planos 
de segurança pública. Por sua vez, os registros de homicídios, foram disponibilizados pela Polícia Civil de Juiz de Fora e se referem aos homicídios tentados, consumados e agressões graves também referentes à área urbana.

Os dados climatológicos de Juiz de Fora foram obtidos junto ao Laboratório de Climatologia e Análise Ambiental, referentes à Estação Climatológica Principal da UFJF/ 50 DISME, contemplaram o período de 1980 a 2010. Devido a interrupções na série ocorridas no ano de 2012 que criaram lacunas no banco de dados e a possibilidade de desenvolvermos análises horárias, optamos em trabalhar nos anos de 2010 a 2012, com dados provenientes da Estação Automática da UFJF/A518. Dentre as variáveis, selecionamos os seguintes elementos: temperatura média compensada, temperatura máxima, temperatura mínima, precipitação total, nebulosidade e pressão atmosférica (no intervalo de 1980 a 2010) e temperatura instantânea (TI), temperatura máxima (TMÁX) e temperatura mínima (TMÍN), entre os anos de 2010 a 2012. Complementando tais informações, foram utilizadas caracterizações da dinâmica atmosférica apresentada por estudos atrelados à região Sudeste, Minas Gerais e Juiz de Fora. Por não termos outras estações ao longo da área urbana, estes dados foram interpretados como constantes para toda área, tendo que desconsiderar suas particularidades.

Os valores médios das temperaturas, por mês, foram calculados seguindo a média aritmética dos horários registrados e dos períodos mensais. Dessa maneira, analisamos as planilhas meteorológicas de cada um dos meses situados entre os anos 1980 a 2010, vinculados à Estação Climatológica Principal/UFJF e, de 2010 e 2012, provenientes da Estação Automática. Tal etapa permitiu descrever o ritmo climatológico do município por mês, estação e ano, destacando suas variações e amplitudes. Estas informações foram tabuladas e representadas graficamente, ressaltando as variações mensais e trienais, não aplicando nenhum ajuste estatístico para corrigir a variação de dias entre os meses, procedendo da seguinte maneira: verão = dezembro (do ano anterior), janeiro e fevereiro; outono = março, abril, maio; inverno = junho, julho e agosto; primavera = setembro, outubro e novembro. Dessa maneira, considerando a quantidade de dias por ano e desconsiderando os anos bissextos, a classe formada pelo verão foi composta por 90 dias, o outono e inverno por 92 dias e a primavera por 91 dias.

Sendo assim, as informações permitiram analisar o comportamento dos registros de homicídios ao longo dos últimos 33 anos, estabelecendo interações entre os diferentes dados e entre as escala municipal e urbana.

\section{3-RESULTADOS E DISCUSSÃO}

\section{1-Aspectos climáticos de Juiz de Fora}


A região sudeste do Brasil, onde está localizado o estado de Minas Gerais e em sua porção sudeste, o município de Juiz de Fora, é certamente uma região caracterizada pelas influências da altitude e disposição do relevo na configuração dos climas regionais, encontrando-se grande parte do território no Planalto Atlântico, que devido à penetração dos ventos pelo litoral, proporcionam umidade nas vertentes a barlavento. O imponente relevo da região impede a manifestação das correntes perturbadas de oeste e noroeste, oriundas de sistemas continentais do interior do Brasil (NIMER, 1989).

$\mathrm{Na}$ região as maiores temperaturas do ano geralmente ocorrem no período de primavera-verão, principalmente entre os meses de dezembro e janeiro e, em contrapartida, as épocas mais frias, no período de outono-inverno, entre os meses de maio e agosto, marcadamente nas ocasiões em que o anticiclone polar gera invasões vigorosas de ar frio. As temperaturas mais altas são frequentemente registradas sob a ação da Massa Tropical Atlântica (MTA) e as mais baixas, sob a ação da Massa Polar Atlântica (MPA). A MTA atua com ventos de norte a nordeste, implicando em tipos de tempo geralmente estáveis e o Anticiclone Polar Atlântico produz incursões de massas frias, sempre precedidas por sistemas frontais geradores de precipitação e acompanhadas de ventos do quadrante sul. É durante a primavera-verão que o aquecimento basal mais forte contribui para a formação de chuvas convectivas, geralmente em dias sob a ação da MTA, contribuindo para a formação de linhas de instabilidade, que ocasionam chuvas torrenciais, geralmente de curta duração. Entretanto, no período de outono-inverno, os totais pluviais diminuem em parte decorrentes da redução dos níveis de umidade das frentes que chegam à região.

Dentre as trinta Estações Meteorológicas Principais de Minas Gerais, administradas pelo Instituto Nacional de Meteorologia e com base nas Normais Climatológicas de 1961-1990, obtém-se uma média de temperatura do ar de $21,3^{\circ} \mathrm{C}$ para o estado mineiro, referencial que situa a cidade de Juiz de Fora como a $5^{a}$ cidade mais fria, apresentando uma média de $19,3^{\circ} \mathrm{C}$, superior apenas aos registros de Barbacena $\left(18,0^{\circ} \mathrm{C}\right)$, Diamantina $\left(18,1^{\circ} \mathrm{C}\right)$, Caparaó $\left(18,8^{\circ} \mathrm{C}\right)$ e São Lourenço $\left(19,1^{\circ} \mathrm{C}\right)$.

Segundo dados da Estação Climatológica de Juiz de Fora (ECP/UFJF), entre os aos de 1980 a 2010, a média da temperatura compensada anual é de $19^{\circ} \mathrm{C}$, apresentando como temperatura média compensada máxima $23,6^{\circ} \mathrm{C}$ (em fevereiro de 2003) e mínima de $13,9^{\circ} \mathrm{C}$ (em julho de 1988). A temperatura média compensada mensal máxima foi de $21,8^{\circ} \mathrm{C}$ (fevereiro) e a mensal mínima de $16,2^{\circ} \mathrm{C}$ (julho). A temperatura média máxima anual foi de $24,4^{\circ} \mathrm{C}$, apresentando extremos máximos de $30^{\circ} \mathrm{C}$ (março/2007) e mínimo de $18,8^{\circ} \mathrm{C}$ (setembro/1983). A temperatura média máxima mensal apresentou pico de $27,4^{\circ} \mathrm{C}$ em fevereiro e média mínima máxima de $21,5^{\circ} \mathrm{C}$ em julho. A média das temperaturas mínimas anual é de $15,4^{\circ} \mathrm{C}$, apresentando máximo em fevereiro $\left(18,1^{\circ} \mathrm{C}\right)$ e mínimo em julho $\left(12,4^{\circ} \mathrm{C}\right)$. Dessa maneira, a amplitude térmica 
mensal das médias foi de $15^{\circ} \mathrm{C}$, tendo em fevereiro a maior frequência dos registros de temperaturas máximas e, em julho, das temperaturas mínimas.

Anualmente, são registrados, em média, $1.555,7 \mathrm{~mm}$, cujos maiores totais se dão frequentemente em dezembro $(301,5 \mathrm{~mm})$ e os menores em agosto $(15,4$ $\mathrm{mm}$ ). Esta sazonalidade térmica e pluviométrica é uma das principais características do clima juiz-forano.

A análise sazonal aponta um verão com temperaturas máximas em torno de $26,6^{\circ} \mathrm{C}$ e mínimas de $17,7^{\circ} \mathrm{C}$, caracterizando tal estação como a mais quente e úmida, já que os totais pluviométricos situam-se em torno de $261,4 \mathrm{~mm}$. Com médias entre $24,6^{\circ} \mathrm{C}$ e $24,2^{\circ} \mathrm{C}$ para as temperaturas máximas e $16,0^{\circ} \mathrm{C}$ e $15,2^{\circ} \mathrm{C}$ para as temperaturas mínimas, respectivamente, as estações de outono e primavera apresentaram valores intermediários, entre a estação mais quente e a mais fria. As menores médias térmicas e pluviométricas são encontradas no inverno, apresentando valores entre $22^{\circ} \mathrm{C}$ e $12,7^{\circ} \mathrm{C}$, cujas precipitações totais ficam em torno de $18,2 \mathrm{~mm}$, indicando um inverno com temperaturas mais amenas e seco. Para melhor compreendermos a atual configuração do espaço urbano juiz-forano, analisaremos algumas mudanças ocorridas na configuração espacial nos últimos anos às comparando com algumas variáveis amplamente utilizadas para definir parâmetros de desenvolvimento humano no urbano.

\section{2-Condições socioeconômicas de Juiz de Fora: Crescimento urbano versus desenvolvimento social}

Nascido como um entreposto comercial ao longo do "Caminho Novo", o município, originalmente denominado Santo Antônio do Paraibuna, foi criado em 1850 e seis anos após, criada a cidade de Juiz de Fora ${ }^{1}$, que favorecida pela abertura da estrada União e Indústria e a implantação de projetos energéticos, passou a exercer influências regionais. Após sucessivas modificações territoriais e administrativas, de acordo com a divisão territorial de 14-V-2001, o município de Juiz de Fora passaria a compor uma área de $1.430 \mathrm{~km}^{2}$ ou $0,24 \%$ do território estadual, localizando Juiz de Fora na porção sudeste do território de Minas Gerais, na mesorregião da Zona da Mata e na microrregião de Juiz de Fora (mapa 1).

De acordo com as informações censitárias (IBGE, Censo 2010) o município apresenta $516.247^{2}$ habitantes $(2,63 \%$ da população estadual, $23,7 \%$ da população da Zona da Mata e $70,8 \%$ da população da microrregião) dentre os

\footnotetext{
1 A cidade é criada em 1856 com o topônimo de Paraibuna, recebendo a denominação de Juiz de Fora em 1865. (IBGE, 2012).

2 Segundo o IBGE (Censo 2010) é possível encontrar dois valores para a população total residente em Juiz de Fora. Nas planilhas que fazem referência os dados dos 853 municípios de Minas Gerais (censo de 2000 e 2010), o total informado é 516.247 hab., enquanto que, nas planilhas que constam os dados por setores censitários de Juiz de Fora, o total informado é $517.872 \mathrm{hab}$.
} 
quais, $98,2 \%$ residem no distrito sede, principalmente na área urbana, que representa $98,9 \%$ da população do distrito.

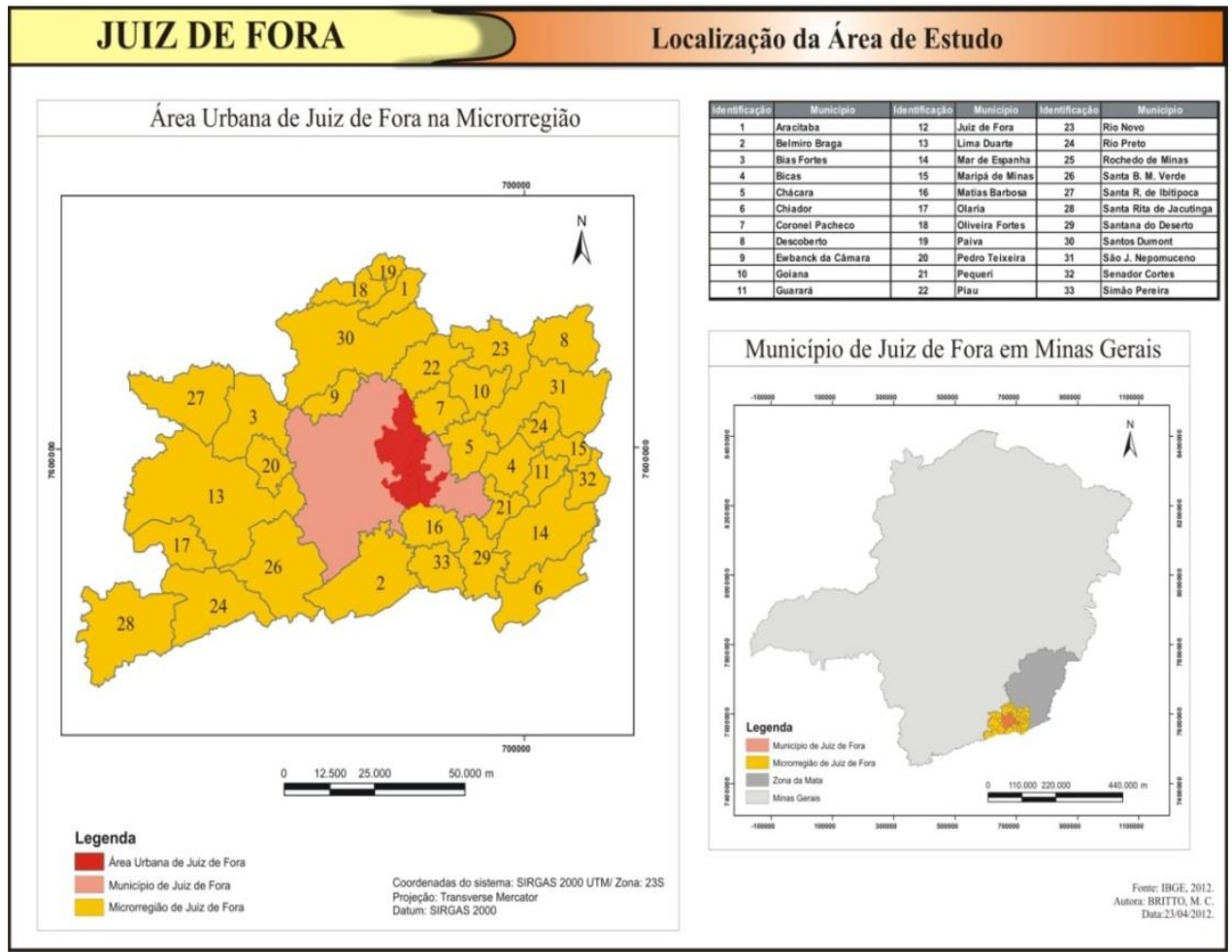

MAPA 1- Localização da área urbana de Juiz de Fora. Fonte: IBGE (2010). Elaboração: BRITTO, M. C., 2012.

A população municipal nos últimos quarenta anos manteve um comportamento crescente, variando de 238.510 hab. (1970) para 517.872 hab. (2010), representando um aumentou $117 \%$, sendo que a maior variação ocorreu entre os anos de 1970 a 1980 (28,9\%) e a menor, entre os anos de 2000-2010 $(13,4 \%)$. Com um dos maiores totais demográficos do estado mineiro, 0 município ampliou e consolidou sua identidade na rede urbana nacional, sendo considerado pelo IBGE como capital Regional B, contudo, as ações dos gestores municipais não evitaram o crescimento das desigualdades econômicas e espaciais.

Segundo o Atlas do Desenvolvimento Humano do Brasil ${ }^{3}$ (PNUD, 2003), entre os anos de 1991 a 2000, os indicadores de desenvolvimento humano de Juiz de Fora (IDH-M) elevaram, refletindo melhorias em três setores: renda, educação e longevidade. Segundo estes dados, o IDH-M passou de 0,769 (Censo-1991), para 0,828 (Censo-2000), situando o município no grupo de alto desenvolvimento humano, principalmente em comparação à sua microrregião,

\footnotetext{
3 Fonte: Elaboração: PNUD/ Atlas de Desenvolvimento Humano do Brasil, 2003, com base no Censo de 2000. Em 2013 foi lançado o Atlas de Desenvolvimento Humano do Brasil 2013, situando o IDH$M$ de Juiz de Fora como Alto, apresentando o valor de 0,778.
} 
com média de 0,74. Em 2013, os dados foram atualizados, e com base nas pesquisas censitárias de 2010, os índices continuaram apontando melhorias no desenvolvimento humano municipal. Todavia, o aparente desenvolvimento humano do município de Juiz de Fora, se deu de forma heterogênea, pois ao atentarmos para a distribuição de renda expressa pelo Coeficiente de $\mathrm{Gini}^{4}$, enquanto a média da microrregião é 0,52 (Censo-2000), Juiz de Fora apresenta o índice de 0,58 (Censo-2000), indicando a mais alta taxa de desigualdade de renda da microrregião.

TABELA 1- Índice de Desenvolvimento Humano Municipal, Índice de Gini e Índice de Vulnerabilidade Familiar da Microrregião de Juiz de Fora e Juiz de Fora. Censo de 1991 e 2000. Fonte: Atlas de Desenvolvimento Humano do Brasil (2003).

\begin{tabular}{|c|c|c|c|c|c|c|}
\hline \multicolumn{7}{|c|}{ IDH-M, GINI E IVF } \\
\hline \multirow{2}{*}{ LOCAL } & \multicolumn{2}{|c|}{ IDH-M } & \multicolumn{2}{c|}{ GINI } & \multicolumn{2}{c|}{ IVF (\%) } \\
\cline { 2 - 7 } & $\mathbf{1 9 9 1}$ & $\mathbf{2 0 0 0}$ & $\mathbf{1 9 9 1}$ & $\mathbf{2 0 0 0}$ & $\mathbf{1 9 9 1}$ & $\mathbf{2 0 0 0}$ \\
\hline Microrregião de Juiz de Fora & 0,656 & 0,737 & 0,53 & 0,52 & 34,06 & 20,31 \\
\hline Juiz de Fora & 0,769 & 0,828 & 0,57 & 0,58 & 18,77 & 11,99 \\
\hline
\end{tabular}

O processo de urbanização Juiz-forano evidencia um quadro controverso do "desenvolvimento" urbano, marcado por positividades e negatividades, onde destacamos o crescimento da violência, sendo os registros de homicídios uma das formas utilizadas na mensuração. Segundo dados disponibilizados pelo SIM/DATASUS, entre os anos de 1991 a 2000 ocorreram 793 óbitos provenientes de homicídios no município e, nas últimas décadas os maiores totais. Somente no triênio 2010-2012, segundo dados disponibilizados pela Polícia Civil, na área urbana de Juiz de Fora, foram registrados 411 ocorrências vinculadas a homicídios. Para melhor compreendermos a dinâmica temporal desses registros, analisaremos as informações por mês, ano, estação e triênio, estabelecendo associações com as variáveis térmicas.

\section{3-Criminalidade violenta na área urbana de Juiz de Fora entre os anos de 2005 a 2011: análise temporal}

Segundo dados disponibilizados pela PMMG/JF (período: 2009-2011) e com base na pesquisa de Lucas (2010), foram registrados na área urbana de Juiz de Fora, entre os anos de 2005 a 2011, 11.410 crimes classificados como violentos. A distribuição mensal demonstrou comportamento crescente de fevereiro a maio, sucedido por valores decrescentes até julho. A partir de então os totais se alternam, apresentando vales em setembro e dezembro, com pequena variação entre outubro e novembro (gráfico 1 ).

\footnotetext{
4 Para fins de esclarecimento, o Coeficiente de Gini, consiste em um número entre 0 e 1 , onde quanto mais perto de 0 mais equitativa será a distribuição, em contrapartida, quanto mais perto de 1 mais concentrada esta será.
} 
Ao associarmos tais informações às variáveis térmicas mensais para o período (2005-2011), o coeficiente de correlação apontou significativa correlação positiva, apresentando $r=0,80$ (temperatura média), $r=0,81$ (temperatura máxima) e $r=0,84$ (temperatura mínima). Segundo a distribuição sazonal, coeficiente de correlação foi mais forte, apresentando $r=0,99$ (temperatura média e temperatura máxima) e $r=0,98$ (temperatura mínima).

Como se observa no gráfico 1 , o mês mais violento foi novembro (1.031 registros) e o menos violento, fevereiro (808 registros) se desvinculando da concepção que o Carnaval poderia elevar, significativamente, o total de registros e que o mês mais quente (fevereiro com $22,1^{\circ} \mathrm{C}$ ) estaria associando aos maiores totais. Salientamos que é também neste período (Carnaval) que o policiamento de rua é ampliado, parte da população se ausenta da cidade e temos o mês mais curto do ano (28 dias).

De fevereiro a maio os totais de registros retomaram o crescimento $(24,7 \%)$ e a partir de maio, se alteram, apresentando pequena variação entre outubro e novembro. Ao longo do período, o mês de agosto mantém variações positivas $(11,9 \%)$, sendo interessante destacar que neste mês ocorre uma grande festa local, a Parada do Orgulho Gay, que movimenta o comércio e o turismo local. Com base na distribuição sazonal, o verão (2.660 registros) se mostrou como a estação menos violenta e a primavera (2.958 registros), como a estação mais violenta (gráfico 2).

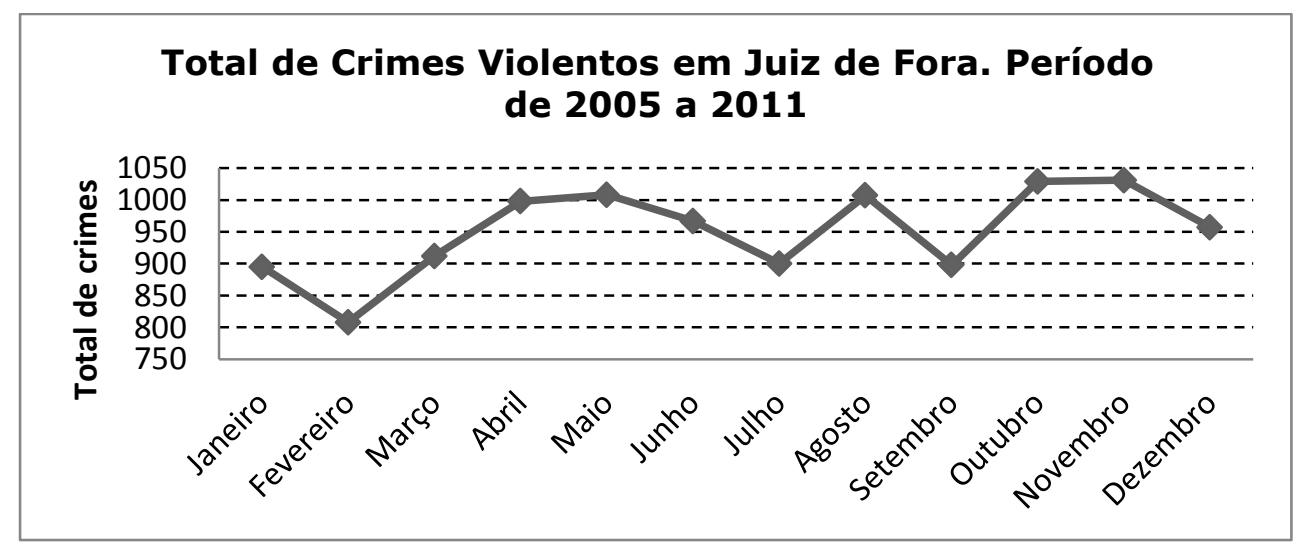

GRÁFICO 1 - Total de registros de crimes violentos em Juiz de Fora, por mês, entre os anos de 2005 a 2011. Fonte: PMMG/4aRISP/JF e Lucas (2010, p. 61). Elaboração: BRITTO, M.C. (2013) 


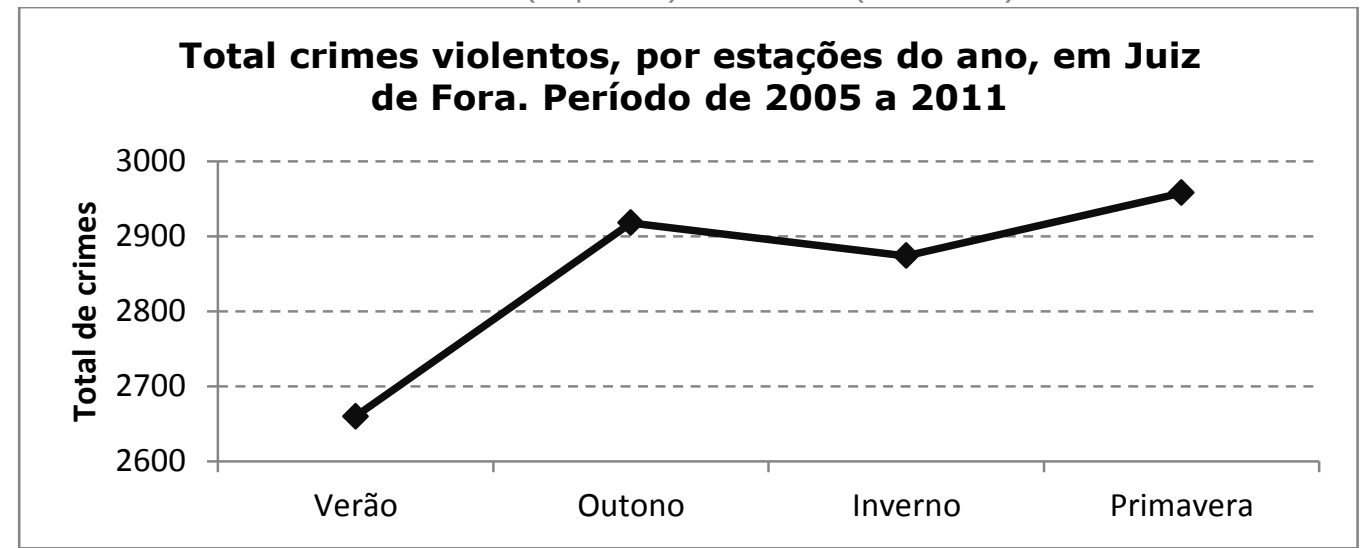

GRÁFICO 2 - Total de registros de crimes violentos em Juiz de Fora, por estações do ano. Período: 2005 a 2011. Fonte: PMMG/4aRISP/JF e Lucas (2010, p. 61). Elaboração: BRITTO, M.C. (2013)

\section{4-Evolução dos registros de óbitos por homicídios no município de Juiz de Fora entre os anos de 1980 a 2010}

Segundo dados disponibilizados pelo SIM/DATASUS, no município de Juiz de Fora, entre os anos de 1980 a 2010, ocorreram 1.119 óbitos provenientes de homicídios, mostrando um comportamento alternado entre as variações anuais, a ponto de distinguirmos três períodos. De 1980 a 1989, os totais variaram entre 26 (1982, 1983, 1986 e 1987) e 38 óbitos (1981), tendo um significativo declínio em 1990, registrando o menor total na série (17 óbitos). De 1991 a 1998, existiram anos com declínio, porém, a frequência dos registros apresentaram valores crescentes e com maior amplitude, variando de 27 para 45 registros, respectivamente. Em 1999, ocorreu um novo declínio, sucedido por aumento em 2000 e uma nova queda em 2001, apresentado sucessões de variações positivas até o ano de 2010 (gráfico 3), com exceção do ano de 2005, quando se registrou o maior vale do período, alternando de 45 para 25 casos, uma variação de $-44,4 \%$. Esse período foi acompanhado em Juiz de Fora por aumentos na população total e das desigualdades sociais, econômicas e espaciais. Concomitantemente, ocorreu também a diminuição das proporções entre o efetivo policial e o total demográfico. 


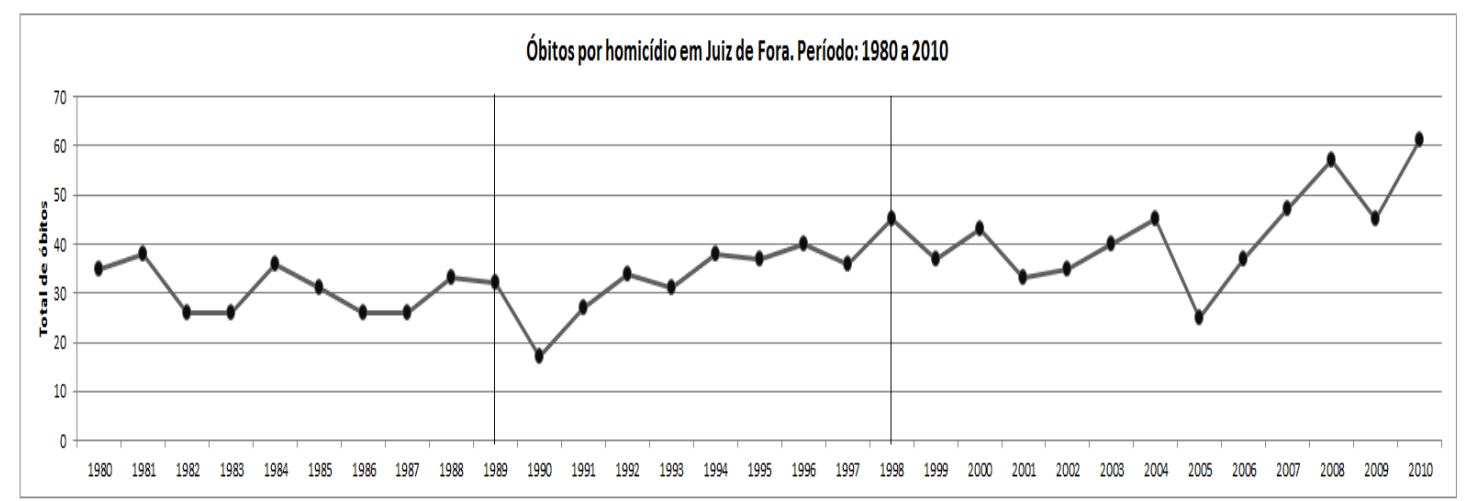

GRÁFICO 3- Total de óbitos por homicídio em Juiz de Fora. Período: 1980 a 2010. Fonte: SIM/DATASUS. Elaboração: BRITTO, M.C. (2013)

Ao longo dos 31 anos analisados, o comportamento dos registros de óbitos não mostrou relações explícitas com as variáveis climáticas, principalmente porque enquanto estas apresentaram comportamento crescente, os dados climatológicos se alternaram próximo da média para o período, apresentando um maior crescimento, na média anual da temperatura máxima. Segundo os coeficientes de correlações, os resultados mostraram fracas relações dos óbitos por homicídio com as variações térmicas e pluviométricas anuais, apresentando os seguintes resultados: $r=0,24$ (temp. compensada), $r=0,43$ (temp. máxima), $r=0,06$ (temp. mínima) e $r=0,22$ (precipitação total), que por sua vez, sinalizam para a relevância de muitas outras variáveis e da necessidade de maiores detalhamentos.

As análises mensais mostraram comportamento decrescente de fevereiro a julho, sendo neste, registrado os menores totais. De agosto a dezembro, os totais gradativamente se elevaram, e deste modo, concentrando os maiores totais em dezembro (113). Salientamos que os meses de novembro e janeiro, registraram variações negativas, comparados a seus antecessores (gráfico 4). 
1 - Média Mensal dos óbitos por homicídio

2- Média Mensal da Temperatura Compensada $\left({ }^{\circ} \mathrm{C}\right)$

3- Média Mensal da Temperatura Máxima $\left({ }^{\circ} \mathrm{C}\right)$

4- Média Mensal da Temperatura Mínima $\left({ }^{\circ} \mathrm{C}\right)$
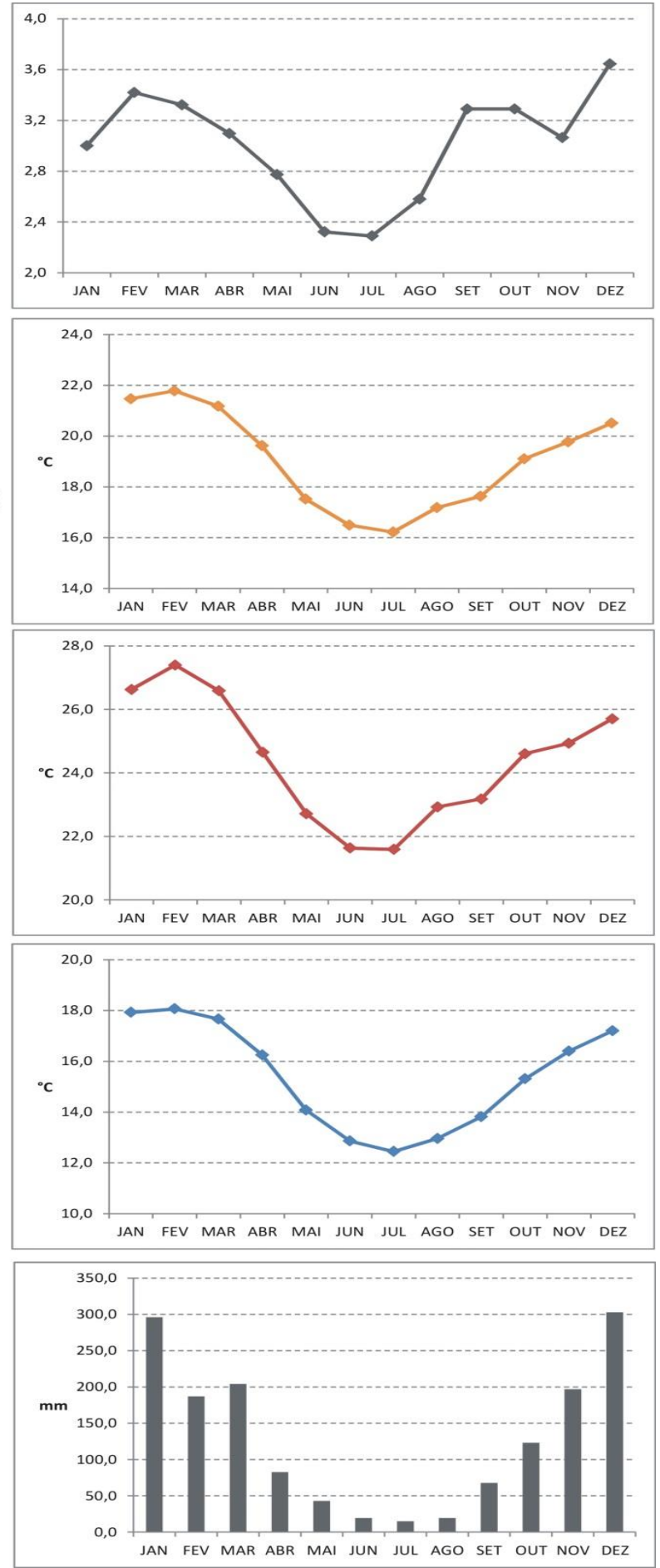

GRÁFICO 4- Temperatura, precipitação e óbitos por homicídio, por mês, em Juiz de Fora. Período: 1980 a 2010. Fonte: SIM/Datasus e Laboratório de Climatologia e Análise Ambiental. Elaboração: BRITTO, M.C.

Os meses com os totais mais representativos se estendem de setembro a fevereiro, acompanhando a elevação da curva térmica e situam-se entre $17,6^{\circ} \mathrm{C}$ (setembro) a $21,8^{\circ} \mathrm{C}$ (fevereiro), apresentando média térmica para o período de Ano 9 - Vol. 13 - JUL/DEZ 2013 
$20^{\circ} \mathrm{C}$ e média dos registros de 3,3 óbitos. Embora os meses de novembro e janeiro apresentem decréscimos, os meses que os sucedem, dezembro e fevereiro destoam no conjunto, apresentando um total médio de 3,6 (dezembro ou 113 óbitos totais no período) e 3,4 (fevereiro ou 106 óbitos totais no período).

Nos meses em que as médias térmicas mensais apresentam queda consecutiva, alternando de $21,2^{\circ} \mathrm{C}$ a $16,2^{\circ} \mathrm{C}$, ou seja, entre março e julho, as médias dos registros também decaíram (2,8 registros), uma vez que os totais situaram entre 103 (março) e 71 (julho). A análise de correlação mensal, entre as variáveis, apresentou resultados significativos: $r=0,78$ (temp. mínima e média), $r=0,79$ (temp. máxima) e $r=0,72$ (precipitação), $r=0,85$ (nebulosidade) e $r=-0,78$ (pressão atmosférica) mostrando uma relativa semelhança entre os resultados, onde salientamos o comportamento inversamente proporcional quando relacionado à pressão atmosférica e, o maior coeficiente de correlação atrelado à associação com a nebulosidade.

Na distribuição trimestral, por estações, a primavera (299 óbitos) e o verão (298), concentraram os maiores volumes de registros e, em contrapartida, no inverno (223) ocorreram os menores totais, representando uma variação de $25,4 \%$. Ao atentarmos para os maiores totais mensais, por ano e por estação (gráfico 5), é perceptível uma relativa homogeneidade entre as estações. Ao todo, foi onze outonos que acumularam os maiores totais, onze primaveras e dez verões, se sobressaindo o maior valor no verão de 2010 (19 óbitos). O inverno, apesar de ter se mostrado com os menores totais durante todo o período, em alguns anos, também apresentou os maiores totais, a se saber: 1987 (8), 1996 (13), 2003(12) e 2004(14), como demonstrado na tabela 2.

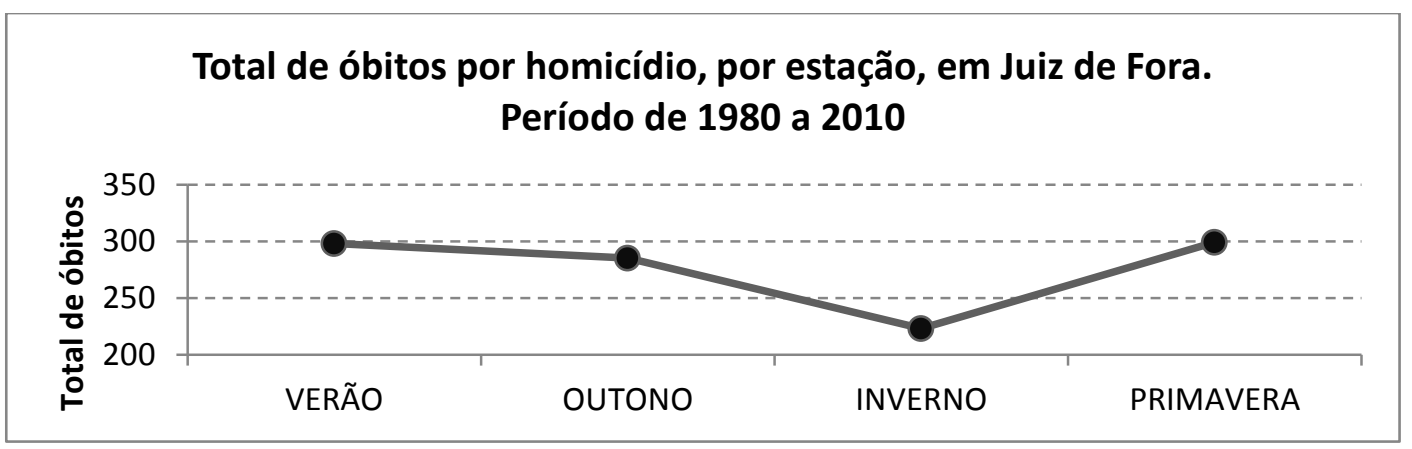

GRÁFICO 5-Total de óbitos por homicídio, por estação, em Juiz de Fora. Período de 1980 a 2010. Fonte: SIM/DATASUS, 2012.

Os menores totais de registros, por ano e por estação, se concentraram significativamente no inverno (21 anos), mesmo registrando o menor total (1 óbito) no outono de 1991 . No restante das distribuições, os totais se mostram próximos, uma vez que, foram oito outonos, seis verões e cinco primaveras, que 
registraram os menores totais de óbitos anuais, como exposto no gráfico 5 e tabela 3.

TABELA 2- Anos em que se registraram os maiores totais de óbitos por homicídio em Juiz de Fora. Período de 1980 a 2010. Fonte: SIM/DATASUS, 2012. Elaboração: BRITTO, M,C., 2013.

\begin{tabular}{|}
$\mid \begin{array}{c}\text { ANOS EM QUE FORAM REGISTRARAM OS MAIORES TOTAIS DE ÓBITOS POR } \\
\text { HOMICÍDIO EM JUIZ DE FORA }\end{array}$ \\
\begin{tabular}{c|c|} 
ANO \\
\hline ESTAÇÃO & $81 ; 82 ; 89 ; 90 ; 92 ; 97 ; 99 ; 02 ; 09 ; 10$. \\
\hline Verão & $83 ; 85 ; 86 ; 87 ; 88 ; 89 ; 90 ; 95 ; 98 ; 00 ; 01$. \\
\hline Outono & $83 ;$ \\
\hline Inverno & $87 ; 96 ; 03 ; 04$. \\
\hline Primavera & $80 ; 84 ; 85 ; 91 ; 93 ; 94 ; 03 ; 05 ; 06 ; 07 ; 08$. \\
\hline
\end{tabular}
\end{tabular}

TABELA 3- Anos em que se registraram os menores totais de óbitos por homicídio em JF. Período de 1980 a 2010. Fonte: SIM/DATASUS, 2012.

\begin{tabular}{|c|c|}
\hline \multicolumn{2}{|c|}{$\begin{array}{l}\text { ANOS EM QUE FORAM REGISTRARAM OS MENORES TOTAIS DE ÓBITOS POR } \\
\text { HOMICÍDIO EM JUIZ DE FORA }\end{array}$} \\
\hline ESTAÇÃO & ANO \\
\hline Verão & $94 ; 86 ; 84 ; 96 ; 01 ; 03$. \\
\hline Outono & $81 ; 82 ; 91 ; 96 ; 99 ; 05 ; 08 ; 09$. \\
\hline Inverno & $\begin{array}{l}80 ; 83 ; 84 ; 85 ; 86 ; 88 ; 89 ; 90 ; 92 ; 93 ; 94 ; 95 ; 98 ; 00 ; 02 ; 05 ; 06 ; \\
07 ; 08 ; 09 ; 10 .\end{array}$ \\
\hline Primavera & $82 ; 87 ; 97 ; 98 ; 04$. \\
\hline
\end{tabular}

Sinteticamente, os dados de óbitos por homicídio e os registros de crimes violentos, anteriormente analisados, apresentaram comportamento crescente de registros na última década, com quedas significativas em fevereiro, junho, julho e no inverno e, acréscimos em agosto e outubro. Estes resultados não excluem a necessidade de complementação futuras, integradas a outras variáveis, mas reforçam a particularidades de cada informação, no processo de compreensão das situações que podem influenciar o contexto de oportunidades para ações violentas, não se posicionando como uma associação de causa-efeito. Contudo, mais uma vez, o mês do fevereiro é caracterizado por quedas, os períodos mais frios aos menores totais de registros, a primavera pelas altas concentrações. 


\section{5-Homicídios na área urbana de Juiz de Fora entre os anos de 2010 a 2012 e sua relação com as variáveis térmicas.}

Entre os anos de 2010 a 2012, as temperaturas instantâneas variaram entre $24,2^{\circ} \mathrm{C}$ (outubro de 2012) a $15,2^{\circ} \mathrm{C}$ (junho de 2011), apresentando média térmica no triênio de $19,2^{\circ} \mathrm{C}$, fator que classifica o ano de 2012 como o mais quente no triênio, apresentando média anual de $19,6^{\circ} \mathrm{C}$. A média das temperaturas máximas foi de $22,7^{\circ} \mathrm{C}$, o que comparativamente às médias anuais $\left(19,7^{\circ} \mathrm{C} / 2010,19,9^{\circ} \mathrm{C} / 2011\right.$ e $\left.28,4^{\circ} \mathrm{C} / 2012\right)$, reforça a observação anterior, classificando o ano de 2012 também como os de maiores médias extremas. Segundo a média das temperaturas mínimas $\left(16,7^{\circ} \mathrm{C}\right)$, o ano de 2012 também foi o mais frio, apresentando média de $13,2^{\circ} \mathrm{C}$, inferior às médias de $2010\left(18,7^{\circ} \mathrm{C}\right)$ e $2011\left(18,2^{\circ} \mathrm{C}\right)$.

Durante o período, foram registrados pela Polícia Civil de Juiz de Fora, 411 ocorrências envolvendo homicídios na zona urbana ${ }^{5}$, cuja distribuição total por mês variou entre 1 (março/2010) a 28 registros (novembro/2012), apontando o mês de março como o de menor total no triênio (15 registros) e setembro (54 registros) e dezembro (52 registros) como os mais violentos, representando uma variação de $260 \%$. Os três primeiros meses do ano configuraram um comportamento decrescente dos registros, enquanto que de maio a setembro, os valores elevaram. Neste mesmo intervalo, abril e setembro exibiram as maiores variações positivas, $186,6 \%$ e $63,6 \%$, respectivamente, configurando as cristas mais significativas. A média para o triênio foi de 11,4 registros/mês, permitindo classificar 20 meses como os mais violentos, dentre eles, quase todos os meses de 2012, exceto janeiro e março. Vale enfatizar que março, ao longo do período, foi o único mês que não apresentou valores acima da média, em contrapartida, setembro, outubro e dezembro acumularam totais superiores à média em todos os anos, como demonstrado na tabela 4.

\footnotetext{
${ }^{5}$ No triênio, 11 registros foram ignorados por se referirem a zonas rurais. Ao todo foram 2 registros em Santa Bárbara do Monte Verde (setembro/2010), 8 registros entre Igrejinha e Valares (1em setembro/2011; 2 em novembro/2011; 1 em agosto/2012; 2 em outubro/2012; $1 \mathrm{em}$ novembro/2012; 1 em dezembro/2012) e 1 registro em Humaitá (maio/2012).
} 
TABELA 4- Total de registros de homicídios em Juiz de Fora no triênio (2010/2012). * Totais acima da média para o período (médio de 11,4

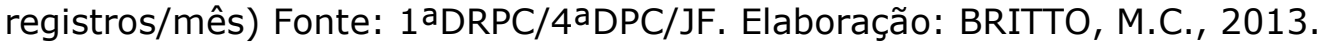

\begin{tabular}{|c|c|c|c|c|c|}
\hline \multirow{2}{*}{ MÊS } & \multicolumn{3}{|c|}{ ANO } & \multirow{2}{*}{ SOMA } & \multirow{2}{*}{ MÉDIA } \\
\cline { 2 - 4 } & $\mathbf{2 0 1 0}$ & $\mathbf{2 0 1 1}$ & $\mathbf{2 0 1 2}$ & & \\
\hline Janeiro & 7 & $12^{*}$ & 10 & $\mathbf{2 9}$ & $\mathbf{9 , 7}$ \\
\hline Fevereiro & 5 & 5 & $12^{*}$ & $\mathbf{2 2}$ & $\mathbf{7 , 3}$ \\
\hline Março & 1 & 4 & 10 & $\mathbf{1 5}$ & $\mathbf{5 , 0}$ \\
\hline Abril & 2 & $18^{*}$ & $23^{*}$ & $\mathbf{4 3}$ & $\mathbf{1 4 , 3 *}$ \\
\hline Maio & 2 & 6 & $13^{*}$ & $\mathbf{2 1}$ & $\mathbf{7 , 0}$ \\
\hline Junho & 6 & 4 & $14^{*}$ & $\mathbf{2 4}$ & $\mathbf{8 , 0}$ \\
\hline Julho & 8 & 2 & $13^{*}$ & $\mathbf{2 3}$ & $\mathbf{7 , 7}$ \\
\hline Agosto & $12^{*}$ & 5 & $16^{*}$ & $\mathbf{3 3}$ & $\mathbf{1 1 , 0}$ \\
\hline Setembro & $15^{*}$ & $16^{*}$ & $23^{*}$ & $\mathbf{5 4}$ & $\mathbf{1 8 , 0}$ \\
\hline Outubro & $16^{*}$ & $17^{*}$ & $14^{*}$ & $\mathbf{4 7}$ & $\mathbf{1 5 , 7 *}$ \\
\hline Novembro & 6 & $14^{*}$ & $28^{*}$ & $\mathbf{4 8}$ & $\mathbf{1 6 , 0 *}$ \\
\hline Dezembro & $11^{*}$ & $17^{*}$ & $24^{*}$ & $\mathbf{5 2}$ & $\mathbf{1 7 , 3 *}$ \\
\hline SOMA & $\mathbf{9 1}$ & $\mathbf{1 2 0}$ & $\mathbf{2 0 0}$ & $\mathbf{4 1 1}$ & - \\
\hline
\end{tabular}

Ao compararmos os totais de homicídios e as médias térmicas, destacamos que o ano de 2012 elevou expressivamente os valores das variáveis analisadas. Ao atermos aos totais de homicídios, por mês, superiores à média do triênio, destacamos que o comportamento apresentado em setembro, outubro e dezembro não foi acompanhado por médias térmicas superiores às médias do triênio (tabela 5). Contudo, os meses de setembro (18 registros) e dezembro (17,3 registros) foram os que apresentaram as médias mais expressivas, sinalizando para um crescimento acima da média que se estende de setembro a dezembro (gráfico 6). Apesar de não contemplar o detalhamento anterior, a análise de correlação mensal apresentou coeficiente de correlação baixo, sendo de $r=0,15$ para temperatura instantânea, $r=0,23$ para temperatura máxima e $r=-0,05$ para temperatura mínima, contribuindo para reforçar que a irregularidade dos registros de homicídios não acompanhou a irregularidade das variáveis térmicas mensais no triênio. 
TABELA 5- Média de registros de temperaturas e homicídios em Juiz de Fora no triênio $(2010 / 2012)$ por mês. * Totais acima da média para o período. Fonte:

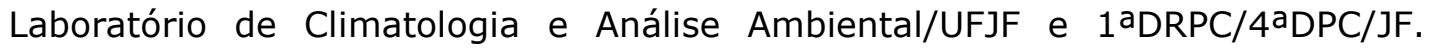
Elaboração: BRITTO, M.C., 2013.

\begin{tabular}{|c|c|c|c|c|c|c|c|c|c|c|c|c|}
\hline \multicolumn{9}{|c|}{$\begin{array}{c}\text { TEMP. INSTANTÂNEA } \\
\left({ }^{\circ} \mathbf{C}\right)\end{array}$} & \multicolumn{3}{c|}{$\begin{array}{c}\text { TEMP. MÁXIMA } \\
\left({ }^{\circ} \mathbf{C}\right)\end{array}$} & \multicolumn{3}{c|}{$\begin{array}{c}\text { TEM. MÍNIMA } \\
\left({ }^{\circ} \mathbf{C}\right)\end{array}$} & \multicolumn{3}{c|}{$\begin{array}{c}\text { TOTAL DE } \\
\text { HOMICÍDIOS }\end{array}$} \\
\hline MÊS & $\mathbf{2 0 1 0}$ & $\mathbf{2 0 1 1}$ & $\mathbf{2 0 1 2}$ & $\mathbf{2 0 1 0}$ & $\mathbf{2 0 1 1}$ & $\mathbf{2 0 1 2}$ & $\mathbf{2 0 1 0}$ & $\mathbf{2 0 1 1}$ & $\mathbf{2 0 1 2}$ & $\mathbf{2 0 1 0}$ & $\mathbf{2 0 1 1}$ & $\mathbf{2 0 1 2}$ \\
\hline JAN & 22,8 & $22,0^{*}$ & $20,1^{*}$ & 23,5 & 22,5 & 28,2 & $22,2^{*}$ & $21,5^{*}$ & 15,1 & 7 & $12^{*}$ & 10 \\
\hline FEV & 22,9 & $23,0^{*}$ & $21,8^{*}$ & 23,5 & $23,7^{*}$ & $31,0^{*}$ & $22,4^{*}$ & $22,4^{*}$ & 16,7 & 5 & 5 & $12^{*}$ \\
\hline MAR & 21,6 & $20,3^{*}$ & $20,9^{*}$ & 22,2 & 20,7 & $30,7^{*}$ & $21,1^{*}$ & $19,8^{*}$ & 15,3 & 1 & 4 & 10 \\
\hline ABR & $19,2^{*}$ & $19,8^{*}$ & $20,0^{*}$ & 19,7 & 20,3 & $28,8^{*}$ & $18,7 *$ & $19,3^{*}$ & 14,9 & 2 & $18^{*}$ & $23^{*}$ \\
\hline MAI & 17,4 & 16,4 & 16,6 & 17,9 & 16,9 & $26,4^{*}$ & $17,0^{*}$ & $16,0^{*}$ & 10,5 & 2 & 6 & $13^{*}$ \\
\hline JUN & 15,4 & 15,2 & 17,4 & 15,9 & $15,7^{*}$ & $25,1^{*}$ & 15,0 & 14,8 & 12,6 & 6 & 4 & $14^{*}$ \\
\hline JUL & 16,9 & 16,2 & 17,0 & 17,3 & 16,7 & $25,7^{*}$ & 16,4 & 15,7 & 9,3 & 8 & 2 & $13^{*}$ \\
\hline AGO & 16,7 & 18,8 & 16,2 & 17,3 & 19,5 & $24,4^{*}$ & 16,2 & $18,2^{*}$ & 10,6 & 12 & 5 & $16^{*}$ \\
\hline SET & 18,3 & 18,4 & 18,6 & 18,8 & 19,1 & $32,4^{*}$ & $17,8^{*}$ & $17,5^{*}$ & 7,2 & 15 & $16^{*}$ & $23^{*}$ \\
\hline OUT & 18,0 & 19,0 & $24,2^{*}$ & 18,6 & 19,5 & $27,9^{*}$ & $17,5^{*}$ & $18,5^{*}$ & 16,2 & 16 & $17^{*}$ & $14^{*}$ \\
\hline NOV & 19,1 & $19,4^{*}$ & 19,0 & 19,6 & $24,0 *$ & $29,5^{*}$ & $18,7^{*}$ & 15,1 & 13,3 & 6 & $14^{*}$ & $28^{*}$ \\
\hline DEZ & $21,5^{*}$ & $19,7^{*}$ & $22,9^{*}$ & 22,1 & 20,2 & $31,3^{*}$ & $21,0 *$ & $19,3^{*}$ & 16,4 & 11 & $17^{*}$ & $24^{*}$ \\
\hline Média & $\mathbf{1 9 , 2}$ & $\mathbf{1 9 , 0}$ & $\mathbf{1 9 , 6}$ & $\mathbf{1 9 , 7}$ & $\mathbf{1 9 , 9}$ & $\mathbf{2 8 , 4}$ & $\mathbf{1 8 , 7}$ & $\mathbf{1 8 , 2}$ & $\mathbf{1 3 , 2}$ & $\mathbf{7 , 6}$ & $\mathbf{1 0 , 0}$ & $\mathbf{1 6 , 7}$ \\
\hline
\end{tabular}

As análises sazonais apontaram como estações mais violentas, a primavera (149 registros) e o verão (103 registros), sinalizando para as estações com temperaturas mais elevadas e para as festividades nacionais de final de ano, sendo que o outono (79 registros) e o inverno (80 registros) apresentaram valores próximos, representando uma queda de 69 casos, ou seja, uma variação de $-46,3 \%$ (tabela 6 e gráfico 7 ).

\section{Total de registros de homicídios, por mês, em Juiz de Fora. Período: 2010-2012}

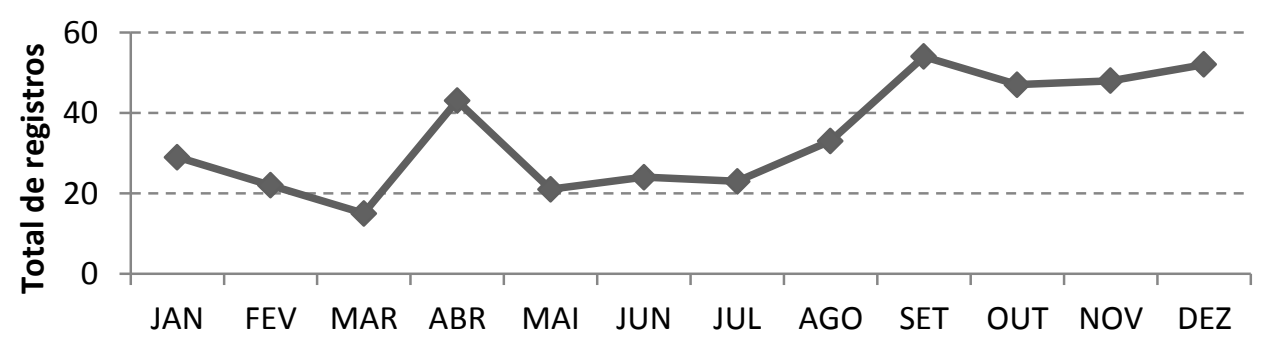

GRÁFICO 6- Total de registros de homicídios, por mês, em Juiz de Fora. Período: 2010-2012. Fonte: $1^{a}$ DRPC/4aDPC/JF. Elaboração: BRITTO, M.C., 2013. 


\begin{tabular}{|c|c|c|c|c|}
\hline \multirow{2}{*}{ ESTAÇÃO } & \multirow{2}{*}{$\begin{array}{c}\text { TOTAL DE } \\
\text { HOMICÍDIOS }\end{array}$} & \multicolumn{3}{|c|}{ TEMPERATURA ( $\left.{ }^{\circ} \mathbf{C}\right)$} \\
\cline { 3 - 5 } & INSTANTÂNEA & MÁXIMA & MÍNIMA \\
\hline VERÃO & 103 & 21,9 & 25,1 & 19,7 \\
\hline OUTONO & 79 & 19,1 & 22,6 & 17,0 \\
\hline INVERNO & 80 & 16,6 & 19,7 & 14,3 \\
\hline PRIMAVERA & 149 & 19,3 & 23,3 & 15,8 \\
\hline SOMA & $\mathbf{4 1 1}$ & - & - & - \\
\hline MÉDIA & $\mathbf{1 0 2 , 8}$ & $\mathbf{1 9 , 2}$ & $\mathbf{2 2 , 7}$ & $\mathbf{1 6 , 7}$ \\
\hline
\end{tabular}

TABELA 6- Total de homicídios e temperatura média, por estações, em Juiz de Fora. Período: 20102012. Fonte: $1^{\mathrm{a} D R P C} / 4^{\mathrm{a} D P C} / \mathrm{JF}$ e Laboratório de Climatologia e Análise Ambiental/UFJF. Elaboração: BRITTO, M.C., 2013.

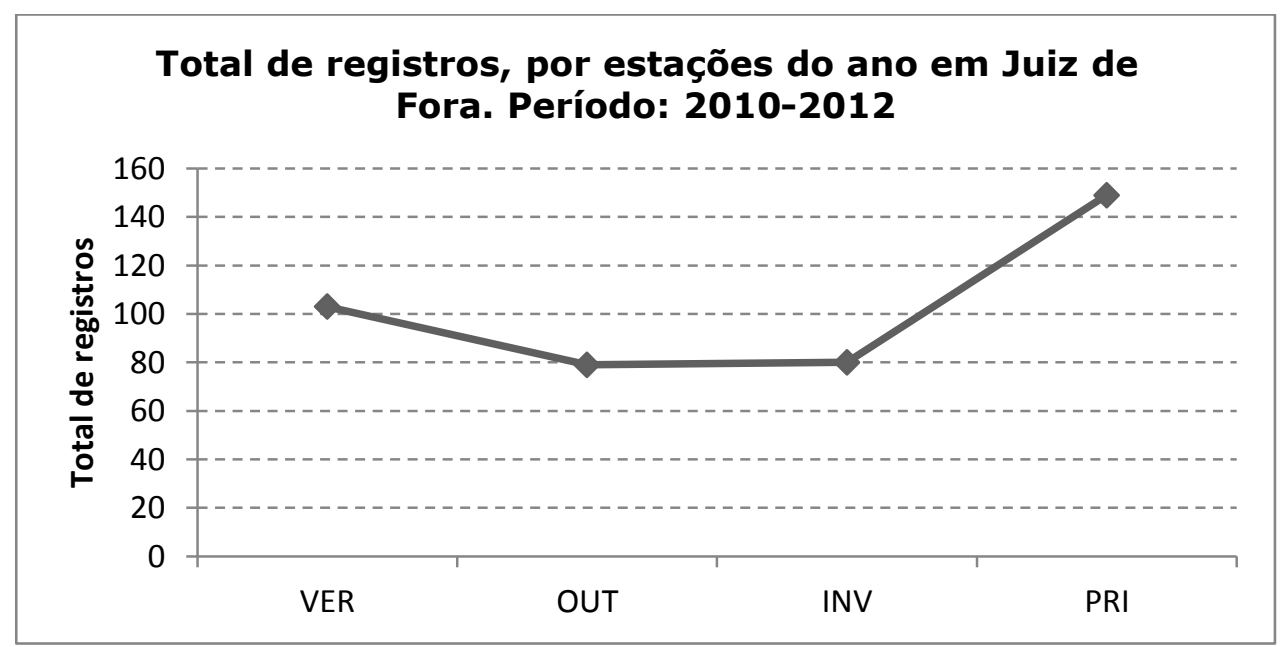

GRÁfico 7- Total de registros de homicídios, por mês, em Juiz de Fora. Período: 2010-2012. Fonte: 1 ${ }^{\mathrm{a} D R P C} / 4^{\mathrm{a} D P C} / \mathrm{JF}$. Elaboração: BRITTO, M.C., 2013.

Mediante a irregularidade diária e por mês, típicas dos dados térmicos, as análises nestes temas foram mais sintéticas, mas nem por isso, menos importantes. Inicialmente, ao atermos a distribuição por variação horária e dias do mês, referentes aos registros de homicídios, não observamos tendências frente ao seu comportamento variável. Contudo, com média em torno de 16,3 registros totais/hora, como se observa no gráfico 8 , os horários que acumularam os maiores totais foram 20:00 (34), 22:00 (33) e 21:00 (31) e, conforme a variação por turnos horários (gráfico 9), os maiores totais de ocorrência concentraram entre $21: 00$ às $02: 59(36,7 \%)$ e $15: 00$ às 20:59 $(30,4 \%)$. 


\section{Total de registros de homicídios em Juiz de Fora,} por hora. Triênio: 2010-2012

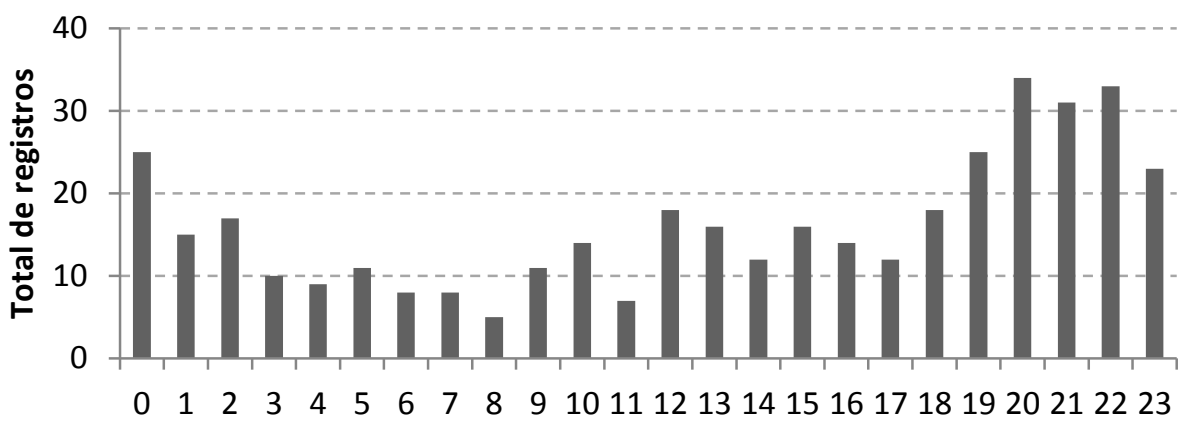

GRÁFICO 8-Total de registros de homicídios em Juiz de Fora, por hora. Período: 2010 a

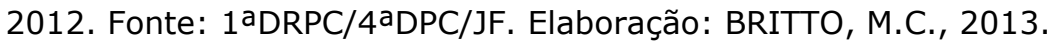

\section{Porcentagem de registros de homicídios em Juiz de Fora, por variação horária. Triênio: 2010-2012}

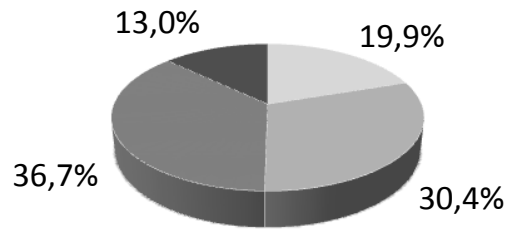

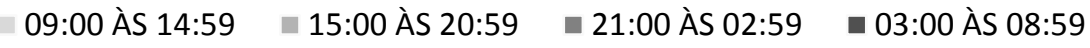

GRÁFICO 9-Porcentagem de registros de homicídios em Juiz de Fora, por variação horária. Período: 2010-2012. Fonte: 1aDRPC/4aDPC/JF. Elaboração: BRITTO, M.C., 2013.

Por meio dessas observações, destacamos que os registros frequentemente ocorreram no período de maior temperatura diária e nos momentos mais propícios a se formarem a ilha de calor urbana. A queda das ocorrências, por outro lado, acompanhou os períodos de maior resfriamento noturno e início do aquecimento matinal, em parte decorrente da redução das atividades coletivas e econômicas, assim como ao costume das populações que consideram esses períodos como os mais destinados ao descanso humano e menos voltados às atividades ao ar livre.

\section{4-CONCLUSÃO}

As análises dos dados referentes aos registros de crimes violentos no período de 2005-2011 sinalizaram para a diminuição dos registros em fevereiro e picos em novembro, negando a hipótese do mês e estação com temperaturas mais elevadas, assim como do Carnaval. Por meio da distribuição sazonal, o verão foi 
apontado como a estação com os menores totais e a primavera como a mais violenta.

Ao focarmos as análises nos totais de óbitos por homicídios ao longo dos anos de 1980 a 2010, abordamos a evolução dos registros no município, alertando para o expressivo crescimento na última década, sendo proporcionalmente superior às variações nos totais demográficos, passando a situar o município, no grupo das segundas maiores taxas estaduais (WAISELFISZ, 2012). Ao agregarmos estes totais às possíveis variáveis explicativas, não observarmos fortes associação com as variáveis climatológicas anuais, ratificadas por meio das análises de correlação. Diferentemente, o ritmo mensal apontou relações com as variáveis de temperaturas (máxima, mínima, média), precipitação, nebulosidade e precipitação, acumulando nos período de maior calor, os maiores picos. Exceções foram observadas nos anos de 1987, 1996, 2003 e 2004, quando no inverno foram registrados os maiores totais anuais.

Ao descrevermos e analisarmos os registros de homicídios, relacionando-os com as variáveis térmicas, genericamente, as informações não sinalizaram para associações expressivas entre as variáveis, tendo na sazonalidade a relação mais curvilínea, onde a primavera e o verão apresentaram os maiores totais. Segundo a distribuição horária, às $00 \mathrm{~h}$ e as $15 \mathrm{~h}$ foram os intervalos horários mais frequentes, assim como o período de 15:00 às 20:59.

Assim acreditamos ter respondido a questão cerne deste artigo, sinalizando para as particularidades de cada fonte e a falta de integração entre elas. É central ao planejamento urbano considerar as instâncias de poder, as condições financeiras e de lazer das comunidades envolvidas, os serviços de saúde, a qualidade de vida, a violência e a criminalidade urbana e, neste jogo, as influências que as condições térmicas exercem na saúde mental. Neste sentido é importante sinalizar para a necessidade de melhorias na qualidade dos dados e da padronização de metodologias que permitam comparações entre os resultados e sua continuidade, enfatizando a necessidade de continuidade dos estudos, visando o desenvolvimento de propostas preventivas e de controle, associadas à saúde e segurança pública. Dessa maneira, em futuros artigos, complementaremos as informações aqui analisadas, incluindo à problemática da dinâmica dos homicídios em Juiz de Fora as heterogeneidades da configuração espacial, o perfil dos atores dos atos e das vítimas e sua interação com as variáveis climáticas. 


\section{5-REFERÊNCIAS BIBLIOGRÁFICAS}

ADORNO, S. Exclusão, socioeconômica e violência urbana. Revista Sociologias, Porto Alegre, ano 4, n.8, 2002, p. 84-135. Disponível em: www.scielo.br/pdf/soc/n8/n8a05.pdf. Acesso: 11/08/2012.

ANDERSON, C. A. Temperature and aggression: Effects on quarterly, yearly, and city rates of violent and nonviolent crime. Journal of Personality and Social Psychology. 1987, 52, p. 1161-1173.

ANDERSON, C. A. Temperature and agression: Ubiquitous effect of heat on occurrence of human violence. Journal Psychological Bulletin. 1989, vol. 106, no 1, p. 74-96.

ANJOS, I. B. dos. Relação de elementos climáticos associados à criminalidade, saúde e rendimentos de grãos no Paraná. Dissertação de mestrado. Departamento de Geografia da Universidade Estadual de Maringá, Maringá, 2003, 144f.

BORGES,V. V., ZAIDAN, R. T., MARTINS, L. A. Mapeamento, zoneamento e análise termal por sensoriamento remoto no município de Juiz de Fora, MG. In: XIII Simpósio Brasileiro de Geografia Física Aplicada, 2009, Viçosa. A Geografia Física Aplicada e as Dinâmicas de Apropriação da Natureza. Viçosa: EDUFV, 2009, p. 1-8.

BREARLEY, H. C. Homicide in the United States. Montclair, NJ: Patterson-Smith, 1932.

BRITTO, M.C., FERREIRA, C. C. M. A interação clima-óbitos por homicídio em Juiz de Fora/MG entre os anos de 1980 a 2010. Revista Geonorte, Edição Especial, v. 2, n. 5, p. 698-710, 2012. Disponível em: http://www.revistageonorte.ufam.edu.br/index.php/edicao-especial-climatologia. Acesso em: 20/12/2012.

BRITTO, M.C., FERREIRA, C. C. M. Aspectos da Relação clima, estacionalidade e criminalidade violenta em Minas Gerais. Revista Geonorte, Edição Especial, v. 2, n. 5, p. 722-734, 2012. Disponível em: http://www.revistageonorte.ufam.edu.br/index.php/edicao-especial-climatologia. Acesso em: 20/12/2012.

BRITTO, M.C., FERREIRA, C. C. M. A interação clima-criminalidade violenta: Dinâmica dos homicídios na cidade de Juiz de Fora entre os anos de 1980 a 2012. In: I Seminário de Graduação e Pós-graduação da Geografia UFJF. Juiz de Fora, 2013.

CHANG, D.H. Environmental influences on criminal activity in Korea. Journal Criminology, 10, 338-352.

CLIMO- Climate and Mortality. Journal Global Health Action. Supplement 1, vol. 5, 2012, 1-91f.

DURKHEIM, E. Divisão do trabalho e suicídio. In: RODRIGUES, J. A. (Org.). Durkheim. São Paulo: Ática, 2001 (Coleção Grandes Cientistas Sociais1).

HAYECK, C. M. Refletindo sobre a violência. Revista Brasileira de História \& Ciências Sociais, ano 1, no 1, p.1-8, 2009.

IBGE, Censo Demográfico 2010. Disponível em: http://www.ibge.gov.br/home/. Acesso em: 05 de junho de 2011.

LACAZ, C. S., et al. Introdução à geografia médica no Brasil. São Paulo: Edgar Blücher/ Editora da Universidade de São Paulo, 1972, $568 f$.

LOMBROSO, C. Crime: Its causes and remedies. Boston: Little, Brown, 1911, 526f.

LUCAS, L. A. P. Análise das ocorrências de crimes contra a pessoa e crimes violentas na cidade de Juiz de Fora/MG entre 2005 e 2008. Dissertação de mestrado. Escola Nacional de Ciências Estatísticas. Mestrado em Estudos Populacionais e Pesquisas Sociais. Rio de Janeiro, 2010.

MENDONÇA, F. Clima e criminalidade: ensaio analítico da correlação entre a temperatura do ar e a incidência da criminalidade urbana. Editora da Universidade Federal do Paraná - UFPR, Curitiba - Paraná, 2001.

MOSER, G. Les stress urbains. Paris: Armand Colin, 1992.

NIMER, E. Climatologia do Brasil. 2ed., Rio de Janeiro: IBGE, 1989, $422 f$. 
NORMAIS CLIMATOLÓGICAS DO BRASIL (1961-1990). Disponível em: www.Ice.esalq.usp.br/angelocci/NORMAIS.xls. Data de acesso: 02/03/2011. PROGRAMA DAS NAÇÕES UNIDAS PARA O DESENVOLVMENTO (PNUD). Atlas de Desenvolvimento Humano. Ano $2003 . \quad$ Disponível em: http://www.pnud.org.br/IDH/Atlas2003.aspx?indiceAccordion=1\&li=li_Atlas2003 ROUQUAYROL, M.Z. Epidemiologia e saúde. $4^{a}$ ed. Rio de Janeiro: MEDSI, 1993. SERRA, A. Os Climas do passado. Revista Brasileira de Geografia, 1954, p. 40-65. SORRE, M. A adaptação ao meio climático e biossocial - Geografia Psicológica. In: MEGALE, J. F. (org.). Max Sorre, São Paulo. Editora Ática, 1984 (Coleção grandes cientistas sociais, 46$)$.

WAISELFISZ, J. J. Mapa da violência dos municípios brasileiros 2012: Os novos padrões da violência homicida no Brasil. versão para web. $1^{\text {a }}$ Edição, 2011, $245 f$. 